\title{
Sudden unexpected death in epilepsy and the song of science
}

\author{
Fulvio Alexandre Scorza
}

Epilepsy is one of the most common serious brain disorders worldwide. Unfortunately, mortality rates are considerably higher in people with epilepsy than would be expected in a healthy population and sudden unexpected death in epilepsy (SUDEP) is the most frequent epilepsy-related category of death ${ }^{1,2}$.

The definition of sudden death in epilepsy differs from that of sudden death in general, as the latter includes deaths with and without an identified pathologic cause ${ }^{2}$. Besides, the lack of autopsy findings and the rarely witnessed cases of SUDEP pose difficulties with regard to definitions of SUDEP. In general terms, SUDEP is defined by precise criteria that were approved in 1997 by an expert panel and is designed as sudden, unexpected, witnessed or unwitnessed, nontraumatic and nondrowning deaths in patients with epilepsy, with or without evidence of a seizure and excluding documented status epilepticus, in which post mortem examination does not reveal a toxicological or anatomical cause of death ${ }^{3}$. Currently, SUDEP is responsible for $7.5 \%$ to $17 \%$ of all deaths in epilepsy and has an incidence among adults between 1:500 and 1:1,000 patientyears ${ }^{4}$. In parallel, a number of associated factors for SUDEP have been reported but the results are not wholly consistent between studies. Thus, the main risk factors evaluated until now include refractoriness of the epileptic condition, presence of generalized tonic-clonic seizures, antiepileptic medication (polytherapy with antiepileptic drugs), young age, duration of the seizure disorder, early onset of epilepsy and winter temperatures ${ }^{5,6}$. Although different mechanisms may play separate roles in different cases $^{5}$, the two major domains of potential mechanisms of SUDEP are autonomic, i.e., respiratory, and cardiovascular ${ }^{7}$. According to the latter, a significant body of literature suggests that SUDEP has a potential cardiac mechanism, due to repetitive cardiac damage during seizures and due to arrhythmia during seizures, possibly triggered by apnea and/or cerebral autonomic imbalance ${ }^{8}$.

From an experimental perspective, although much has been learned from animal studies about structural, chemical, and physiological changes that contribute to seizures and epilepsy, the development of experimental preparations that closely model the human SUDEP phenomenon is essential, since could provide vital information to aid elucidation of the pathogenetic mechanisms of SUDEP and stimulate investigation into possible therapeutic strategies'. Following this line of reasoning, the experience of our research group makes us increasingly believe that some chronic models of temporal lobe epilepsy are important tools for the study of cardiovascular abnormalities in epilepsy and may even be relevant for the understanding of the SUDEP phenomenon. In 2005, we used the pilocarpine model in order to evaluate the heart rate from rats with epilepsy in vivo (ECG) and in an isolated ex vivo preparation (Langendorf preparation) ${ }^{10}$. In brief, we demonstrated a significant increase in baseline heart rate in vivo of animals with epilepsy (346 $\pm 7 \mathrm{bpm}$ ) when compared with control group animals (307 $\pm 9 \mathrm{bpm})$. Quite
Fulvio Alexandre Scorza

Rua Botucatu 862

04023-900 São Paulo SP - Brasil

E-mail: scorza.nexp@epm.br

\section{MORTE SÚBITA E INESPERADA NAS EPILEPSIAS E A CANÇÃO DA CIÊNCIA}

Experimental Neurology. Universidade Federal de São Paulo (UNIFESP). São Paulo SP, Brasil. 
interesting, we did not find differences in the isolated $e x$ vivo situation (control animals: $175 \pm 7 \mathrm{bpm}$; animals with epilepsy: $176 \pm 6 \mathrm{bpm})$, suggesting that autonomic modulation of the heart is changed in rats with epilepsy, which could explain the appearance and maintenance of an increased basal heart rate in these animals ${ }^{10}$. Recently, we also analyzed heart rate in rats subjected to electrical kindling of the amygdala ${ }^{11}$. The main purpose of our study was to evaluate changes in baseline heart rate and heart rate responses during stage 5 of kindling, which corresponds to generalized seizures ${ }^{11}$. Briefly, the animals did not show significant differences in basal heart rate before and after electrode implantation. On the other hand, basal heart rate was higher during stage 5 of kindling, possibly resulting from sympathetic activation caused by the epileptic condition. Furthermore, we also observed an intense bradycardia occurred at the beginning of seizure, followed by a rebound tachycardia. Interestingly, our results indicated that the intensity of the tachycardia is direct related to the number of generalized seizures. Accordingly, these results allow us to describe that repeated generalized tonic-clonic seizures directly affect sympathetic outflows ${ }^{11}$.

Returning to the clinical field, what are the best actual proposals to minimize the occurrence of SUDEP? It is clear that SUDEP is mainly (but not exclusively) a problem for people with chronic uncontrolled epilepsy ${ }^{12}$, but our understanding of the best way to prevent it is still incomplete. Thus, some strategies ${ }^{13}$ have been suggested that could be useful in reducing the risk of SUDEP:

[1] Good control of seizures;

[2] Reduction of stress;

[3] Participation in physical activity and sports;

[4] Dietary management (e.g., omega-3 supplementation);

[5] Supervision at night;

[6] Family members' knowledge of cardiopulmonary resuscitation (CPR) techniques and the basics of defibrillator use ${ }^{13}$.

On balance, as a complete understanding of all the risk factors, mechanisms, and specific methods to prevent SUDEP is yet to be obtained, caution is really prudent and necessary. In this sense, we are totally in agreement with previous studies ${ }^{14,15}$ that, if there is a reasonable chance of preventing SUDEP, it must be discussed with all patients with epilepsy at the highest risk of SUDEP. The physician can then explain possible strategies that people with epilepsy and their families can take to try to reduce their risk of SUDEP. Furthermore, modern neuroscientists recognizes that epilepsy-related mortality is a significant public health issue and should be closely monitored by governments that manage health care in their respective countries. Obviously, trying to solve these problems is never an easy task, The American Epilepsy Society and the Epilepsy Foundation Joint Task Force already initiated a task force to assess the state of knowledge (research directions, social, cultural and educational efforts) on SUDEP ${ }^{16}$.

Finally, these stop/go decisions on SUDEP field developed recently by epileptologists is exactly what the new science called the translational research, which indicates the integration of the advancements in basic science with clinical trials, taking research from bench to bedside ${ }^{17}$.

\section{REFERENCES}

1. Duncan JS, Sander JW, Sisodiya SM, Walker MC. Adult epilepsy. Lancet 2006;367:1087-1100.

2. Nashef $L$, Ryvlin P. Sudden unexpected death in epilepsy (SUDEP): update and reflections. Neurol Clin 2009;27:1063-1074.

3. Nashef L. Sudden unexpected death in epilepsy: terminology and definitions. Epilepsia 1997;38(Suppl):S6-S8.

4. Schuele SU, Widdess-Walsh P, Bermeo A, Lüders HO. Sudden unexplained death in epilepsy: the role of the heart. Cleve Clin J Med 2007;74 (Suppl): S121-S127.

5. Surges R, Thijs RD, Tan HL, Sander JW. Sudden unexpected death in epilepsy: risk factors and potential pathomechanisms. Nat Rev Neurol 2009;5:492-504.

6. Scorza FA, Colugnati DB, Pansani AP, Sonoda EY, Arida RM, Cavalheiro EA. Preventing tomorrow's sudden cardiac death in epilepsy today: what should physicians know about this? Clinics 2008; 63:389-394.

7. So EL. What is known about the mechanisms underlying SUDEP? Epilepsia 2008:49:93-98.

8. Stollberger C, Finsterer J. Cardiorespiratory findings in sudden unexplained/ unexpected death in epilepsy (SUDEP). Epilepsy Res 2004;59:51-60.

9. Striano P, Zara F. Epilepsy: a 'going ape' model for SUDEP? Nat Rev Neurol 2009;12:639-640.

10. Colugnati DB, Gomes PA, Arida RM, et al. Arq Neuropsiquiatr 2005;63:10351041.

11. Pansani AP, Colugnati DB, Sonoda YFE, et al. Tachycardias and sudden unexpected death in epilepsy: a gold rush by an experimental route. Epilepsy Behav 2010 (in press).

12. Tomson T, Nashef L, Ryvlin P. Sudden unexpected death in epilepsy: current knowledge and future directions. Lancet Neurol 2008;7:1021-1031.

13. Scorza FA, Arida RM, Terra VC, Cavalheiro EA. What can be done to reduce the risk of SUDEP? Epilepsy Behav 2010; 18:137-138.

14. Hirsch $\sqcup$, Hauser WA. Can sudden unexplained death in epilepsy be prevented? Lancet 2004;364:2157-2158.

15. Brodie MJ, Holmes GL. Should all patients be told about sudden unexpected death in epilepsy (SUDEP)? Pros and Cons. Epilepsia 2008;49:99-101.

16. So EL, Bainbridge J, Buchhalter JR, et al. Report of the American Epilepsy Society and the Epilepsy Foundation joint task force on sudden unexplained death in epilepsy. Epilepsia 2009;50:917-922.

17. Goldblatt EM, Lee WH. From bench to bedside: the growing use of translational research in cancer medicine. Am J Transl Res 2010;2:1-18. 